\title{
Eosinophilic fasciitis
}

\author{
Ka Lai Tsoi, ${ }^{1}$ Martijn Custers, ${ }^{2}$ Liesbeth Bij de Vaate, ${ }^{3}$ Johannes W G Jacobs ${ }^{1}$
}

${ }^{1}$ Rheumatology Department, University Medical Center Utrecht, Utrecht, Netherlands;

${ }^{2}$ Rheumatology Department, Maartenskliniek, Woerden, Netherlands;

${ }^{3}$ Internal Medicine Department, Zuwe Hofpoort Ziekenhuis, Woerden, Netherlands

Correspondence to Ka Lai Tsoi, kalaitsoi@hotmail.com

\section{Summary}

A 57-year-old woman presented with malaise and heaviness in her extremities. At first there were no clues of an inflammatory disease, but the patient developed slowly progressive oedema of her arms and legs with induration of the skin. Blood tests showed eosinophilia. Additional analysis revealed generalised lymphadenopathy. After excluding an infectious or malignant cause, the clinical diagnosis of eosinophilic fasciitis was made, this was confirmed by the results of a full thickness skin biopsy.

\section{BACKGROUND}

Here, we present a case of eosinophilic fasciitis, which is an unusual diagnosis but explains the symmetric signs and symptoms of the extremities with skin changes and peripheral blood eosinophilia in this patient. The aetiology of eosinophilic fasciitis is not understood. It is a relatively unknown disease for clinicians. Therefore, it is important to raise clinical awareness of this rare disease. Furthermore, we describe typical findings at physical examination for this disease discriminating it from clinically similar diseases.

\section{CASE PRESENTATION}

A 57-year-old Caucasian woman was referred to the outpatient clinic of rheumatology with malaise and heaviness in her extremities. Her medical history revealed hypothyroidism, which was treated with thyroid hormone substitution. The first rheumatologic investigation revealed no clues for an inflammatory disease. The symptoms were diagnosed as postviral myalgia. Meanwhile, the symptoms and signs progressed slowly. The patient developed oedema of the arms and legs with induration of the affected skin. The oedema ranged from distally to proximally in the left leg and also developed in the right leg, the forearms and later in the neck and face. The skin of the hands and feet was spared. Initially the swellings were painless, later they became tender. Also, thickening of the affected skin occurred. There were no signs of arthritis; she had no fever. She reported some weight loss. There were no signs of an autoimmune disease, like a malar erythema, photosensitivity, mucous membrane lesions, Raynaud phenomenon, ocular or oral dryness or uveitis. The patient did not smoke. She used alcoholic drinks infrequently. Regarding her family history, her mother had had rheumatoid arthritis and her father had lung cancer.

Physical examination showed a normal blood pressure, heart rate and temperature. Oedema was present in the neck and below the lower eyelids; the latter was accompanied with erythema. Telangiectasia was seen on the skin of the chest. Auscultation of the heart and lungs was normal. Liver and spleen were not enlarged. There was severe, generally non-pitting oedema of the forearms and legs. The affected skin felt thickened. A 'groove sign' was present (figure 1). The patient did not have sclerodactyly or synovitis. Nail fold capillaroscopy was normal.

\section{INVESTIGATIONS}

Laboratory results showed an erythrocyte sedimentation rate of $26 \mathrm{~mm} /$ first $\mathrm{h}$, leucocytosis $\left(12.8 \times 10^{9} / \mathrm{l}\right)$ with eosinophilia $\left(1.7 \times 10^{9} / 1\right)$, normal $\mathrm{C}$ reactive protein and creatine kinase levels and a negative anti-nuclear antibody test. The triple faeces test was negative. Chest $\mathrm{x}$-ray and ultrasound examination of the abdomen were normal. Venous insufficiency of the lower extremities was excluded on Doppler ultrasound analysis. However, inguinal lymphadenopathy was seen. On CT of the abdomen there were also multiple enlarged lymph nodes (maximal diameter of $14 \mathrm{~mm}$ ) seen in the retroperitoneum and in the para-iliacal regions. A total excision biopsy of an enlarged inguinal lymph node showed aspecific reactive changes and no signs of malignancy. Bone marrow analysis demonstrated normal bone marrow with a significant amount of eosinophilic granulocytes. There were no signs of a myelodysplastic disorder or mastocytosis. The clinical diagnosis eosinophilic fasciitis was made. A deep biopsy of the leg was performed showing panniculitis and myofasciitis with eosinophilic infiltrations (figure 2). The clinical diagnosis of eosinophilic fasciitis was confirmed.

\section{TREATMENT}

Prednisone at a daily dose of $60 \mathrm{mg}$ was started; the patient also received medication to prevent osteoporosis.

\section{OUTCOME AND FOLLOW-UP}

A few days after starting prednisone, the peripheral eosinophilia disappeared. Also the oedema diminished and the skin of the extremities became more supple. At the time of writing, 8 months after the diagnosis, the patient is doing well. Prednisone is being tapered, currently she is receiving 
A

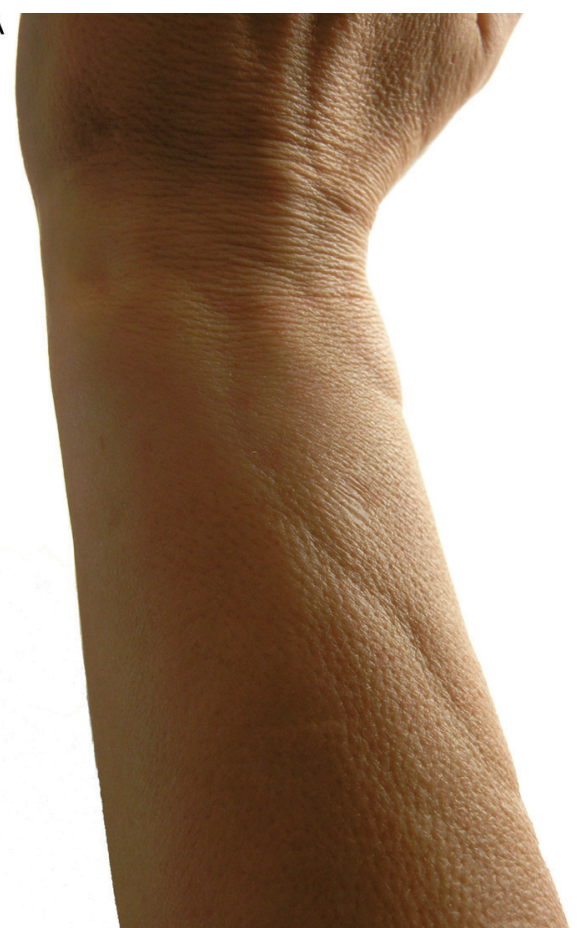

B

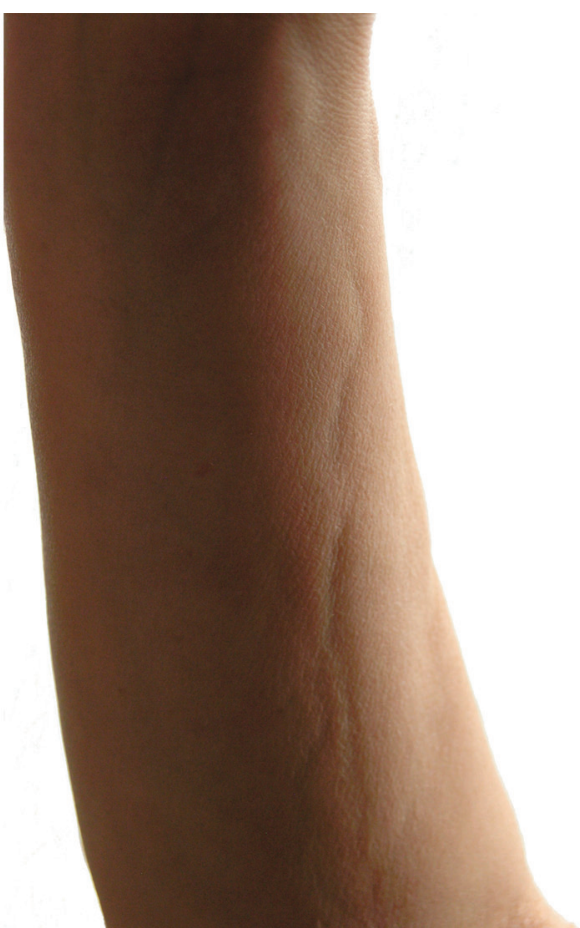

Figure 1 Forearm with venous furrowing ('groove sign'); (A) extensor surface, (B) fl exor surface..

12.5 milligrams per day. Although residual skin changes are still present, including the 'groove sign', there are no other signs of activity of the disease.

\section{DISCUSSION}

Eosinophilic fasciitis (Shulman's syndrome) is a rare disease of unknown aetiology. The syndrome of diffuse fasciitis and eosinophilia was first described in 1974 by Shulman. ${ }^{1}$ Since then, over 250 cases have been reported. The disorder is characterised by symmetrical swelling and skin induration of the distal portions of the arms and/ or legs, accompanied by peripheral blood eosinophilia. ${ }^{1}$ Initially, oedema of the affected areas is present, accompanied by pain or tenderness. ${ }^{2}{ }^{3}$ Eventually, the skin develops a peau d' orange aspect, which may become indurated and evolving into a scleroderma-like appearance. Physical examination classically reveals venous furrowing, the 'groove sign'. Induration and sclerosis of subcutaneous tissue can result in joint contractures. In contrast to systemic sclerosis, in eosinophilic fasciitis the skin of hands and feet is usually spared and there is no sclerodactyly. Also, the presence of the Raynaud phenomenon and involvement of internal organs are uncommon. Inflammatory arthritis can be seen as an extracutaneous manifestation. ${ }^{3}$

Besides systemic sclerosis, the differential diagnosis of swelling and skin thickening includes several diseases and disorders. Morphea is a localised fibrosing disorder, charactarised by one or more sclerotic skin lesions on the trunk or limbs. Sclerodactyly is absent in morphea. Eosinophilia is not typical for morphea. Complex regional pain syndrome is accompanied by pain and swelling of a limb and limited range of motion and autonomic dysregulation. However, involvement of both arms and legs is unusual. In nephrogenic systemic fibrosis, thickening and hardening based on dermal fibrosis of the skin occur in patients with advanced renal failure after administration of gadolinium. The skin of trunk and extremities including the hands and feet are frequently involved. Our patient did not receive gadolinium. Myxoedema related to thyroid dysfunction typically presents with swelling of pretibial areas or the dorsum of the foot. Scleroedema of Buschke can occur in diabetes mellitus and is characterised by symmetrical skin thickening particularly on the shoulders and back. Scleromyxoedema is associated with paraproteinaemias and presents with yellow-red papules on typically the face, neck, forearms and hands. The lesions can progress to a thickened and indurated skin. Acrodermatitis chronica atrophicans is a skin manifestation of Lyme disease, in one extremity; the extensor surface of hands and feet are commonly involved. The first stage is characterised by swelling, limb atrophy is a late sign. The toxic oil syndrome caused by ingestion of adulterated rapeseed oil, results in limb oedema with a scleroderma appearance, eosinophilia and lungs involvement. ${ }^{4}$ Our patient did not use adulterated rapeseed oil. The eosinophilia-myalgia syndrome is associated with ingestion of contaminated preparation of L-tryptophan and mimics eosinophilic fasciitis. ${ }^{5}$ However, compared to eosinophilic fasciitis, visceral involvement is seen more often in the eosinophilia-myalgia syndrome. None of these differential diagnoses were likely in our patient.

Laboratory analysis in eosinophilic fasciitis typically shows peripheral blood eosinophilia, an elevated erythrocyte sedimentation rate and hypergammaglobulinaemia. ${ }^{1}$ However, laboratory data does not always correlate with disease severity in eosinophilic fasciitis. ${ }^{3}$ Laboratory abnormalities can be transient and are therefore not mandatory for the diagnosis.

A full thickness incisional skin biopsy (down to superficial muscle) is helpful to confirm the diagnosis. 


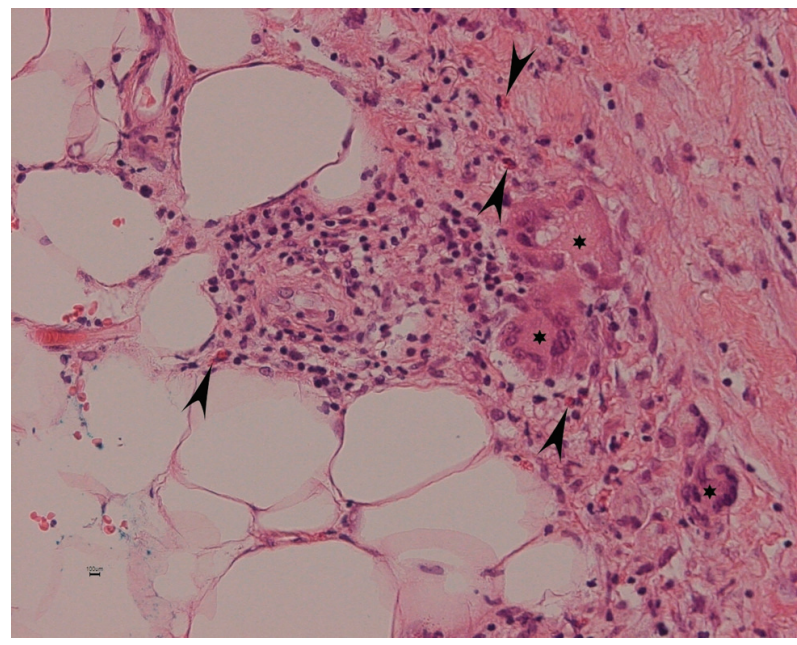

Figure 2 A full thickness skin biopsy specimen shows infi Itration of histiocytes, lymphocytes, eosinophils (arrows) and multi-nucleated giant cells (asterisks) in the deep fascia (H\&E, x200).

Histologically, pronounced thickening of the subcutaneous fascia is generally considered to be the most distinctive feature of eosinophilic fasciitis. ${ }^{6}$ Eosinophilia of the fascia may be seen, but is not required for the diagnosis. ${ }^{3}$ The histological abnormalities change while the disease progresses. Early in the course of the disease the deep fascia and lower subcutis are oedematous and infiltrated with lymphocytes, plasma cells, histiocytes and eosinophils. In a later stage these structures and eventually the dermis become collagenised, thickened and sclerotic. ${ }^{7}$ At MRI also fascial thickening can be seen. ${ }^{8}$

Systemic application of glucocorticoids is generally considered as the initial therapeutic agent of choice. Usually, a high dose regimen is used. Controlled trials are lacking. Various therapies have also been applied, like D-penicillamine, chloroquine, cimetidine, azathioprine, cyclosporine, photochemotherapy and infliximab. ${ }^{3} 10$ Evaluation of the effects of a treatment can be difficult, since spontaneous remission of the disease may occur. ${ }^{3}$

Regarding disease outcome, morphea-like skin lesions, a younger age (under 12 years) at onset, trunk involvement or histopathological dermal fibrosclerosis are associated with residual fibrosis in eosinophilic fasciitis. ${ }^{11}$ Complications of eosinophilic fasciitis are joint contractures, peripheral polyneuropathy and a compartment syndrome..$^{12} 13$ Sporadically, a malignancy can present as eosinophilic fasciitis as a paraneoplastic syndrome, in most cases before the cancer is diagnosed. In particular associations with haematolymphoid malignancies have been described. ${ }^{14}$ Relative unresponsiveness to glucocorticoid therapy is reported to be a red flag for cancer associated eosinophilic fasciitis
Learning points

- Eosinophilic fasciitis is a rare disorder, characterised by symmetrical swelling and skin induration of extremities, accompanied by peripheral eosinophilia and a late phase scleroderma-like appearance generally without involvement of hands and feet.

- A typical clinical sign is the 'groove sign'.

- Unlike in systemic sclerosis, sclerodactyly, the Raynaud phenomenon and internal organ involvement are generally absent in eosinophilic fasciitis.

- A full thickness skin to muscle biopsy shows pronounced thickening of the subcutaneous fascia; eosinophilia may be seen, but is not required for the diagnosis.

- Systemic glucocorticoids are considered to be the initial therapeutic agent of choice.

Acknowledgements The authors would like to thank Professor Dr M R van Dijk, who performed the histological analysis at the department of Pathology, University Medical Center Utrecht.

Competing interests None.

Patient consent Obtained.

\section{REFERENCES}

1. Shulman LE. Diffuse fasciitis with eosinophilia: a new syndrome? Trans Assoc Am Physicians 1975;88:70-86.

2. Rodnan GP, DiBartolomeo A, Medsger TA JrProceedings: Eosinophilic fasciitis. Report of six cases of a newly recognized scleroderma-like syndrome. Arthritis Rheum 1975;18:525

3. Lakhanpal S, Ginsburg WW, Michet CJ, et al. Eosinophilic fasciitis: clinical spectrum and therapeutic response in 52 cases. Semin Arthritis Rheum 1988; 17:221-31

4. Tabuenca JM. Toxic-allergic syndrome caused by ingestion of rapeseed oil denatured with aniline. Lancet 1981:2:567-8.

5. Pfanner TP, Person DA, Berenberg JL, et al. Eosinophilia/myalgia syndrome associated with L-tryptophan. Lancet 1990;335:353-5.

6. Bennett RM, Herron A, Keogh L. Eosinophilic fasciitis. Case report and review of the literature. Ann Rheum Dis 1977;36:354-9.

7. Barnes L, Rodnan GP, Medsger TA, et al. Eosinophilic fasciitis. A pathologic study of twenty cases. Am J Pathol 1979;96:493-518.

8. De Clerck LS, Degryse HR, Wouters E, et al. Magnetic resonance imaging in the evaluation of patients with eosinophilic fasciitis. J Rheumatol 1989;16:1270-3.

9. Antic M, Lautenschlager S, Itin PH. Eosinophilic fasciitis 30 years after what do we really know? Report of 11 patients and review of the literature. Dermatology (Basel) 2006;213:93-101.

10. Drosou A, Kirsner RS, Welsh E, et al. Use of infliximab, an anti-tumor necrosis alpha antibody, for inflammatory dermatoses. J Cutan Med Surg 2003; 7:382-6

11. Endo $Y$, Tamura A, Matsushima $Y$, et al. Eosinophilic fasciitis: report of two cases and a systematic review of the literature dealing with clinical variables that predict outcome. Clin Rheumatol 2007;26:1445-51.

12. Moriguchi M, Terai $\mathrm{C}$, Kuroki $\mathrm{S}$, et al. Eosinophilic fasciitis complicated with peripheral polyneuropathy. Intern Med 1998;37:417-20.

13. Niskanen L, Tulla H, Fräki J, et al. Compartment syndrome as a late complication of eosinophilic fasciitis. J Rheumatol 1989;16:1364-5.

14. Naschitz JE, Rosner I, Rozenbaum M, et al. Rheumatic syndromes: clues to occult neoplasia. Semin Arthritis Rheum 1999;29:43-55. 


\section{BMJ Case Reports}

This pdf has been created automatically from the final edited text and images.

Copyright 2012 BMJ Publishing Group. All rights reserved. For permission to reuse any of this content visit http://group.bmj.com/group/rights-licensing/permissions.

BMJ Case Report Fellows may re-use this article for personal use and teaching without any further permission.

Please cite this article as follows (you will need to access the article online to obtain the date of publication).

Tsoi KL, Custers M, Bij de Vaate L, Jacobs JWG. Eosinophilic fasciitis. BMJ Case Reports 2012;10.1136/bcr.2012.6158, Published XXX

Become a Fellow of BMJ Case Reports today and you can:

- Submit as many cases as you like

- Enjoy fast sympathetic peer review and rapid publication of accepted articles

- Access all the published articles

- Re-use any of the published material for personal use and teaching without further permission

For information on Institutional Fellowships contact consortiasales@bmjgroup.com

Visit casereports.bmj.com for more articles like this and to become a Fellow

Keep up to date with all published cases by signing up for an alert (all we need is your email address) http://casereports.bmj.com/cgi/alerts/etoc 